RESEARCH REPORT

\title{
A multilevel analysis of socioeconomic (small area) differences in household food purchasing behaviour
}

\author{
G Turrell, T Blakely, C Patterson, B Oldenburg
}

J Epidemiol Community Health 2004;58:208-215. doi: 10.1136/jech.2003.011031

See end of article for authors' affiliations

....................

Correspondence to: Dr G Turrell, School of Public Health, Queensland University of Technology, Victoria Park Road, Kelvin Grove, Brisbane,

Queensland, Australia, 4059;

g.turrell@qut.edu.au

Accepted for publication 28 July 2003
Study objective: To examine the association between area and individual level socioeconomic status (SES) and food purchasing behaviour.

Design: The sample comprised 1000 households and 50 small areas. Data were collected by face to face interview (66.4\% response rate). SES was measured using a composite area index of disadvantage (mean 1026.8, SD =95.2) and household income. Purchasing behaviour was scored as continuous indices ranging from 0 to 100 for three food types: fruits (mean 50.5, SD=17.8), vegetables $(61.8,15.2$ ), and grocery items $(51.4,17.6)$, with higher scores indicating purchasing patterns more consistent with dietary guideline recommendations.

Setting: Brisbane, Australia, 2000.

Participants: Persons responsible for their household's food purchasing.

Main results: Controlling for age, gender, and household income, a two standard deviation increase on the area SES measure was associated with a 2.01 unit increase on the fruit purchasing index $195 \% \mathrm{Cl}$ -0.49 to 4.50$)$. The corresponding associations for vegetables and grocery foods were $0.60(-1.36$ to $2.56)$ and $0.94(-1.35$ to 3.23). Before controlling for household income, significant area level differences were found for each food, suggesting that clustering of household income within areas (a composition effect) accounted for the purchasing variability between them.

Conclusions: Living in a socioeconomically advantaged area was associated with a tendency to purchase healthier food, however, the association was small in magnitude and the $95 \% \mathrm{Cl}$ for area SES included the null. Although urban areas in Brisbane are differentiated on the basis of their socioeconomic characteristics, it seems unlikely that where you live shapes your procurement of food over and above your personal characteristics.
A large literature shows that socioeconomic groups differ in their rates of mortality and morbidity for cardiovascular disease, type 2 diabetes, and many cancers, with the socioeconomically disadvantaged experiencing the poorest health. ${ }^{12}$ Diet plays a part in the onset and progression of these degenerative conditions, ${ }^{3-5}$ and it is increasingly believed that dietary differences between socioeconomic groups contribute in part to their different health profiles for chronic disease. ${ }^{67}$

Most studies investigating the relation between socioeconomic status (SES) and diet have focused on individual level factors. Sampled individuals are grouped on the basis of similar socioeconomic characteristics such as occupation, education, or income, and these groupings are compared in terms of their dietary behaviours or food and nutrient intakes. Studies of this type often show that socioeconomically disadvantaged groups are least likely to engage in behaviours that accord with healthy eating messages, ${ }^{89}$ and they are more likely to have food and nutrient intake profiles that parallel their higher rates of diet related disease. ${ }^{10} 11$

During the past decade, researchers have increasingly called for a greater focus on the potential contribution of environments and places in terms of shaping and circumscribing the health related behaviour of people. ${ }^{12-14}$ It is argued that an improved understanding of the determinants of behaviour, and by extension, more effective approaches to advancing health, will necessarily require studies that consider the person, their context or setting (for example, neighbourhood, work, family), and interactions between these. Dietary studies of this type have been conducted in Britain, ${ }^{15-19}$ Finland, ${ }^{20}{ }^{21}$ and the USA..$^{22-24}$ Despite differences in analytical method, and heterogeneity of area unit, sample size, or how diet was measured, each study found evidence that area characteristics might influence diet independent of individual level characteristics. The findings of some of these studies, however, are challengeable, as they were based on statistical methods that did not allow for the partitioning of area and individual level sources of variation (that is, between contextual and compositional effects). Less open to challenge are the findings of multilevel studies, which do allow for this partitioning, and of the few that have examined area variations in diet, each has provided suggestive evidence that both individual and contextual factors separately influence diet. ${ }^{19} 2325$ Specifically, these studies showed that residents of socioeconomically disadvantaged areas had poorer dietary intakes after adjusting for individual level SES, suggesting that unmeasured features of the wider social and physical environment in disadvantaged areas acted to hinder the procurement and consumption of a healthy diet.

British and US researchers have identified a number of possible explanations for dietary differences between urban areas that vary in their socioeconomic characteristics. Firstly, some socioeconomically disadvantaged areas are underserved by large supermarkets, ${ }^{12} 2526$ and as a result, residents are disproportionately reliant on smaller shops, which typically stock a limited range of foods, their prices are higher, and fresh food is often of a lesser quality. Secondly, socio-

Abbreviations: BFS, Brisbane food study; SSD, statistical sub-division; $C C D$, census collectors district; IRSD, index of relative socioeconomic disadvantage; ABS, Australian Bureau of Statistics; SES, socioeconomic status 
economically disadvantaged groups sometimes experience difficulties accessing large (and often distant) shopping facilities because they lack private transport, or live in areas where public transport is inadequate or non-existent, ${ }^{27-29}$ which also increases the likelihood that a greater amount of food is purchased from smaller local shops. Thirdly, healthy foods (that is, those consistent with dietary guideline recommendations) have been found to be less readily available in shops located in socioeconomically disadvantaged areas, and also more expensive than their less healthful equivalents. ${ }^{30} 31$

In this paper, we add to the international evidence base about context effects on diet by examining small area variations in food purchasing behaviour among residents of Brisbane City, Australia. Specifically, we use multilevel modelling to determine whether there is variation between socioeconomically different areas in the purchase of fruits, vegetables, and grocery foods after controlling for personal and household sociodemographic characteristics. Significant area level variation independent of individual and household level factors would raise the possibility that urban regions in Australia are differentiated on the basis of food availability, accessibility, and affordability, making the procurement of healthy food difficult for socioeconomically disadvantaged groups. In the US and Britain two societal level processes have probably contributed to area variations in diet. Firstly, these countries have witnessed markedly increased spatial segregation of their populations along social and economic lines. ${ }^{32-34}$ Secondly, this increasing socioeconomic polarisation appears to have been accompanied by concomitant changes to the structure and organisation of the food retail industry, such that supermarkets and large stores have disinvested in, and relocated from urban disadvantaged areas to regions characterised by large population size and density, higher average incomes, and reduced operating costs. ${ }^{35} 36$ While urban areas in Australia are also socially and economically segregated, ${ }^{37}$ the nature and extent of this separation appears qualitatively different (that is, less extreme) than that observed elsewhere. In addition, this country has not seemingly undergone similar changes to the food retailing industry. As a result, it remains an open question whether or not urban areas in Australia are differentiated in their dietary behaviours in ways that are found in the US and Britain..$^{38}$

\section{METHODS}

The data were collected as part of the 2000 Brisbane food study (BFS). Details of the study's scope and coverage, its research design, sampling procedures, data collection methods, and representativeness have been published elsewhere. ${ }^{39}$ Only a brief overview is provided here.

\section{Sample design}

The BFS was conducted in the Brisbane City Statistical SubDivision (SSD). The sample comprised 1000 households and 50 census collectors districts (CCD), and was selected using a stratified two stage cluster design. A CCD is the smallest administrative unit used by the Australian Bureau of Statistics (ABS) to collect census data. As at 1996, the Brisbane SSD consisted of 1517 contiguous CCD, each containing an average of 200 occupied private dwellings. Stratification consisted of ranking the CCD on the basis of each area's index of relative socioeconomic disadvantage (IRSD) score. A CCD's IRSD score is derived by the ABS using principal components analysis, and it reflects the overall level of socioeconomic disadvantage of each area measured on the basis of attributes such as low income, low educational attainment, high levels of public sector housing, high unemployment, and jobs in relatively unskilled occupations. ${ }^{40}$
The IRSD scores used in this study were calculated from data collected in the 1996 Australian census. The distribution of IRSD scores was subsequently divided into 10 strata (deciles) and five CCD were selected from each of the strata using systematic without replacement probability proportional to size sampling. The spatial and socioeconomic characteristics of the 50 CCD are presented in figure 1. As would be predicted from the stratification process, the sampled CCD differed markedly on all key socioeconomic indicators.

Stage 2 involved selecting 1000 private dwellings from the 50 CCD (20 dwellings on average per CCD), and this was undertaken using simple random sampling. Given the focus of the study, we interviewed the person within each dwelling who was primarily responsible for most of the food shopping. A final response rate of $66.4 \%$ was achieved. ${ }^{39}$

\section{Data collection}

The individual level data collection within each CCD occurred between September and December 2000, and was conducted on the basis of face to face interviews. Interviews lasted an average of one hour, and respondents were offered a small financial gratuity (AUS\$10). The interview sought information on food purchasing choices, factors influencing choice, shopping practices, subjective perceptions of food availability and food prices, food expenditure, food and nutrition knowledge, and the sociodemographic characteristics of the respondent and other household head (if a couple household). Although the data were collected from a single individual, the interview questions elicited information about food purchasing patterns for the household as a whole.

\section{Measures}

Area level SES for each CCD was measured using its IRSD score (see above).

Individual level SES was measured by the study participant's estimate of total household income (including pensions, allowances, and investments) collected as a 14 category variable and subsequently re-coded into four categories for analysis: (1) less than AUS\$20 799, (2) \$20 800-36 399, (3) $\$ 36400-51999$, and (4) \$52, 000 or more. Households in categories 1 and 2 received incomes at or below the Australian average as at 2000, and those in categories 3 and 4 , above the average. ${ }^{41}$ Household income was used as the socioeconomic indicator for three reasons. Firstly, income is a well established and important determinant of dietary quality, and affects directly a family's ability to afford and procure food. ${ }^{42}$ Secondly, household income was likely to capture the socioeconomic characteristics of all people living in the household (reflecting individual level incomes, and to some extent education and occupation) and therefore presumably embodied most of the within household socioeconomic processes influencing food choice. Thirdly, it seemed appropriate (substantively and analytically) to examine the relation between SES and food purchasing using variables that were each measured at the same level (that is, household), thus improving model specificity and fit.

Foods purchased for each household were classified into two broad groups: grocery items (including meat and chicken), and fruit and vegetables. Grocery purchasing was examined on the basis of 16 questions, each of which had two or more response categories. For example, respondents were asked: "When you go shopping, what type of bread do you usually buy?" The response options included: I do not buy bread, white, wholemeal, multigrain, white high in fibre, rye, soy and linseed, plus others. Multiple responses were permitted for each question. The other 15 questions were structured in an identical manner and pertained to rice, pasta, baked beans, fruit juice, tinned fruit, milk, cheese, yoghurt, beef mince, chicken, tinned fish, vegetable oil, 


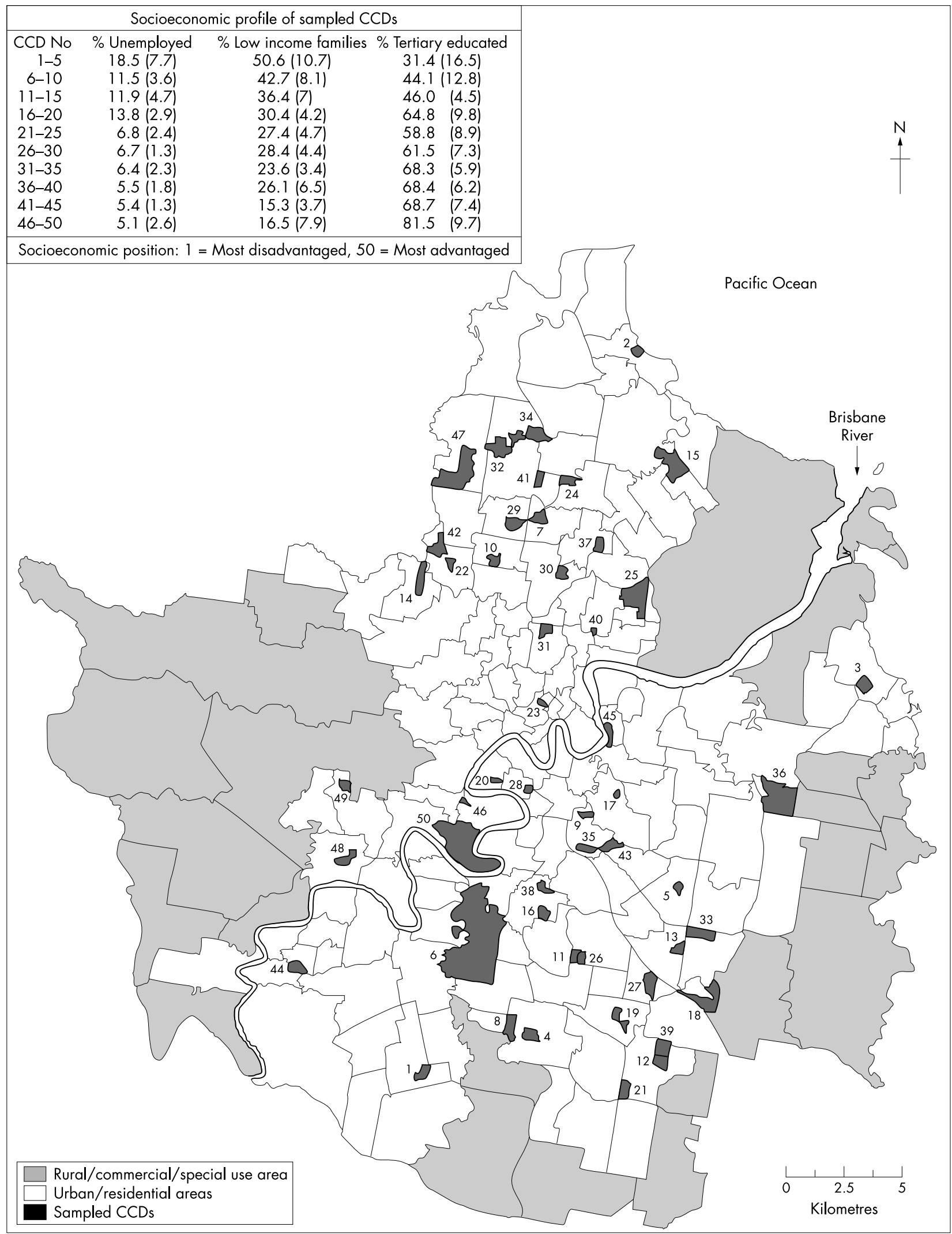

Figure 1 Sampled census collectors districts (CCDs) in the Brisbane statistical sub-division and their socioeconomic characteristiscs.

margarine, butter, and solid cooking fat. In Australia, health promotion and education campaigns ${ }^{43}$ directed at disseminating dietary guideline messages ${ }^{44}$ recommend that people purchase and consume a variety of nutritious foods that are comparatively high in fibre, and low in fat, salt, and sugar. In keeping with these campaigns, we classified respondents' 


\begin{tabular}{|c|c|c|}
\hline Food type & Recommended $t$ & Regular \\
\hline Bread & \multicolumn{2}{|l|}{$\begin{array}{l}\text { Wholemeal, multigrain, white high in fibre, rye, White } \\
\text { soy and linseed }\end{array}$} \\
\hline Rice & Wholemeal or brown & White \\
\hline Pasta & Wholemeal or brown & White \\
\hline Baked beans & Salt reduced or unsalted & Regular salt \\
\hline Fruit juice & No added sugar (unsweetened) & $\begin{array}{l}\text { Added sugar, fruit drink (5\%-35\% fruit } \\
\text { juice) }\end{array}$ \\
\hline Tinned fruit & In natural juice & In syrup \\
\hline Milk & $\begin{array}{l}\text { Reduced fat (Trim), low fat (Skim), high calcium } \\
\text { (Physical, Shape), high calcium skim (Physical), } \\
\text { high iron (Life), high protein (Lite White), reduced } \\
\text { lactose (Lactaid), no cholesterol (Dairy Wise), soy } \\
\text { or soy \& linseed (Skim) }\end{array}$ & $\begin{array}{l}\text { Extra creamy, full cream, soy, or soy and } \\
\text { linseed (full cream) } \\
\text { d } \\
\text { y }\end{array}$ \\
\hline Cheese & Reduced fat ( $25 \%$ less fat), low fat $(<10 \%$ fat) & Full fat \\
\hline Yoghurt & Low fat (plain and fruit) & Full fat (plain and fruit) \\
\hline Beef mince & Lean (trim/premium) & Regular (choice/fine grade) \\
\hline Chicken & $\begin{array}{l}\text { Breast fillet without skin, thigh fillet without skin, } \\
\text { drumstick without skin }\end{array}$ & $\begin{array}{l}\text { Breast fillet with skin, thigh fillet with skin, } \\
\text { drumstick with skin, wings, whole chicken } \\
\text { with skin }\end{array}$ \\
\hline Tinned fish & In spring water & In oil or brine \\
\hline Vegetable oil & $\begin{array}{l}\text { Canola, sunflower, safflower, olive, corn, soy } \\
\text { sesame }\end{array}$ & $\begin{array}{l}\text { Peanut, sesame, blended edible, } \\
\text { macadamia }\end{array}$ \\
\hline Margarine & Salt reduced, fat reduced & Regular salt, full fat \\
\hline Butter & Salt reduced, unsalted & Regular salt \\
\hline Solid cooking fat & Margarine, solidified oil & $\begin{array}{l}\text { Solid animal fat (lard, beef dripping), } \\
\text { vegetable shortening }\end{array}$ \\
\hline \multicolumn{3}{|c|}{$\begin{array}{l}{ }^{*} \text { The food types are based on the five core food groups of the Australian Guide to Healthy Eating }{ }^{43} \text { and findings of } \\
\text { the } 1995 \text { Australian National Nutrition Survey. }{ }^{46} \text { tFood options endorsed in dietary guideline publications and } \\
\text { considered preferable choices to minimise risk for the development of diet related diseases. }{ }^{44}\end{array}$} \\
\hline
\end{tabular}

food purchasing choices into a "recommended" and "regular" category (table 1).

Purchasing patterns for each grocery food type were then scored as follows. Respondents were categorised as never purchasing the food (scored 0), as purchasing the regular option exclusively (scored 1), as purchasing a variety of food that included both the recommended and regular options (scored 2), or as purchasing the recommended option exclusively (scored 3 ). The food types were then summed to form a purchasing index, and using an approach described elsewhere, ${ }^{845}$ the index scores were adjusted to account for the fact that some people did not purchase particular foods. This index was then scaled to range from range from 0 to 100 , with high scores being indicative of greater compliance with dietary guideline recommendations.

Fruit purchasing information was elicited using a question that asked "When shopping for fresh fruit, how often do you buy these types"? The respondent was instructed to include seasonal fruits, but exclude fruit juice, tinned fruit, and dried fruit. The question item set consisted of 19 fruits selected from the food frequency questionnaire used in the 1995 Australian National Nutrition Survey. ${ }^{46}$ Respondents were asked to indicate their usual fruit purchasing pattern on the basis of five point scales that ranged from never buy (scored 0 ) to always buy (scored 4). A fruit purchasing index was created by summing the items, and scoring the measure to range from 0 to 100. Higher scores indicated that respondents regularly purchased many different types of fruits when shopping for their household (that is, a high score was obtained by reporting "Always" or "Nearly always" for most of the fruits listed). In addition, high scores were consistent with two of the Australian Dietary Guideline recommendations, namely, "Eat a wide variety of nutritious foods", and "Eat plenty of....vegetables (including legumes) and fruits" ${ }^{44}$

Vegetable purchasing behaviour was measured using an identical format and method to that used for fruit. Respondents were asked to indicate how often they purchased 21 vegetables (including fresh and frozen, but excluding tinned or dried) using five point items. These were subsequently summed to form an index and re-scored to range from 0 to 100 , with higher scores being interpreted in the same way that was outlined for fruit purchase.

\section{Analysis}

Table 2 presents descriptive statistics for each of the measures used in this analysis. Of the 1000 households interviewed for the BFS, 24 declined to answer the income question, four did not know the income of other people in their household, and two provided insufficient information for their food purchasing behaviours to be reliably assessed. Each of these respondents was excluded, resulting in a final useable sample of 970.

The data were analysed as a two level random intercept variance components model, using MLwiN version 2.1c. ${ }^{47}$ Three models were specified for each food purchasing behaviour. Firstly, a null model, comprising individuals (level 1) nested in CCDs (level 2) with no predictor variables in the fixed part of the model. Substantive interest for the null model focuses on the CCD level random term, which if significant (indicated using $\chi^{2}$ ), suggests between area variation in food purchasing behaviour. For the null (and all other) models the intraclass correlation was calculated to estimate the percentage of total variance in food purchasing behaviour that was between the CCD (the remaining percentage is between individual variation). The null model was subsequently extended to include fixed effects for age, sex, and household income (model 2) and then the exposure of interest in this study: area socioeconomic disadvantage (model 3). The effect size for the area SES variable was expressed as a two standard deviation increase in area SES, which is equivalent to the difference in area SES score between the median values for the top and bottom quartiles of the area SES index. Improvements in the fit of the three nested models due to the successive inclusion of the fixed effect variables were assessed using the deviance statistic. 
Table 2 Descriptive statistics for the fixed effect variables and food purchasing indices

\section{Fixed effect variables}

Sex of main food purchaser $(n, \%)^{*}$

Male

Female

Household income (n, \%)

$\$ 52000$ or more

$\$ 36400-51999$

$\$ 20800-36399$

$\leqslant \$ 20799$

Age of main food purchaser (mean, SD)

Area socioeconomic disadvantage (mean, SD) $†$

Food purchasing indices (mean, SD) $\ddagger$

Fruit

Vegetables

Grocery

$\begin{array}{ll}207 & 21.3 \\ 763 & 78.7 \\ 407 & 42.0 \\ 173 & 17.8 \\ 206 & 21.2 \\ 184 & 19.0 \\ & 45.2(16.7) \\ & 1026.8(95.2)\end{array}$

$50.5(17.8)$

$61.8(15.2)$

$51.4(17.6)$

*Interviews were conducted with the person in each household who was primarily responsible for food shopping, and given that women typically purchased the food, they represented $78.7 \%$ of the final sample. $†$ Area scores ranged from 634.8 to 1184.2 , with lower scores indicating greater socioeconomic disadvantage. \#Each food purchasing index was scored to range from 0-100, with higher indicating greater compliance with dietary guideline recommendations.

\section{RESULTS}

Table 3 presents the multilevel results for fruit purchasing behaviour. The CCD level random term was significant $\left(\chi^{2}=4.96, p=0.025\right)$ indicating that the average purchasing score was not constant across the 50 small areas. Of the total variability, $4.1 \%$ occurred between CCD and $95.9 \%$ between individuals. Thus while the vast majority of the variance in fruit purchasing behaviour was accounted for by individual level factors, the null model tentatively suggested that area characteristics might also independently contribute to this behaviour. Model 2 adds the fixed effect terms for age, sex, and household income. The coefficients and 95\% CI indicate that older persons, women, and high income households had significantly higher fruit purchasing scores. The inclusion of these fixed effect terms significantly increased the overall fit of this model relative to the null model $\left(\chi^{2}=153.9\right.$, $\mathrm{p}<0.0001)$. The variance of the CCD level random term, however, was reduced to non-significance after adjustments for compositional variations based on age, sex, and household income $\left(\chi^{2}=2.09, p=0.147\right)$. Model 3 adds the fixed term for area socioeconomic disadvantage, and this was only moderately related with fruit purchasing. A two standard deviation increase on the area based SES measure was associated with a 2.01 unit increase on the fruit purchasing

\section{Key points}

- In the US and Britain, area level socioeconomic status is associated with food and nutrient intake and dietary behaviour independent of individual level socioeconomic characteristics

- Within Brisbane City, Australia, there is no convincing association between area level socioeconomic status and food purchasing behaviour

- Much of the apparent association of area socioeconomic status with food purchasing in Brisbane was attributable to confounding by household income, thus the clustering of household income within areas (a composition effect) accounted for the food purchasing variability between them

- Despite urban areas in Brisbane being differentiated in their socioeconomic characteristics, this does not seem to influence the procurement of healthy food, which is in contrast with that found in other countries index, and the confidence intervals included null (95\% CI -0.49 to 4.50 ). The inclusion of area SES made a negligible contribution to the fit of the fruit purchasing model $\left(\chi^{2}=2.43, p=0.119\right)$. For a model that included area SES but not household income (results not shown), a two standard deviation increase in area SES was associated with a 3.97 unit increase on the fruit purchasing index (95\% CI 1.55 to 6.40 ).

Tables 4 and 5 present the equivalent results for vegetable and grocery purchasing respectively. The null models for both vegetable and grocery purchase showed that no statistically significant variation was evident at the CCD level: vegetables $\left(\chi^{2}=0.613, p=0.433\right)$, grocery foods $\left(\chi^{2}=0.581, p=0.445\right)$. In other words, apart from non-systematic sampling fluctuations, there were no differences in the purchasing scores among the 50 areas. The inclusion of the fixed terms for age, sex, and household income (model 2) showed that these factors significantly improved the fit of each model (results for deviance tests not reported). For both vegetable and grocery purchasing, average index scores were significantly higher for older persons, women, and residents of high income households. Area SES was only weakly related with the purchase of vegetables and grocery foods (model 3). A two standard deviation increase on the area SES measure was associated with a 0.60 unit increase on the vegetable purchasing index (95\% CI -1.36 to 2.56 ) and a 0.94 unit increase on the grocery index (95\% CI -1.35 to 3.23$)$. The inclusion of area SES produced no statistically significant improvement in the fit of the models for vegetable and grocery purchasing. For models that included area SES but not household income, a two standard deviation increase in area SES was associated with a 1.86 unit increase on the vegetable index (95\% CI 0.00 to 3.73 ) and a 3.22 unit increase on the grocery purchasing index ( $95 \%$ CI 1.04 to 5.39 ).

\section{DISCUSSION}

Multilevel studies conducted in the US and Britain have found evidence in support of contextual or neighbourhood socioeconomic effects on diet independent of individual level factors. ${ }^{19} 2325$ Typically, residents of socioeconomically disadvantaged areas have poorer diets than those in more advantaged areas. Our study in the Brisbane metropolitan region suggests that small area variation in the purchase of fruit, vegetables, and grocery foods mainly reflect spatial differences in the socioeconomic composition of the people living in the areas. Much of the apparent association of area SES with food purchasing was attributable to confounding by 
Table 3 Area and individual level effects on fruit purchasing (random intercept models)*

\begin{tabular}{|c|c|c|c|c|c|c|}
\hline \multirow[t]{2}{*}{$\begin{array}{l}\text { Areas }=50 \\
\text { Individuals }=970\end{array}$} & \multicolumn{2}{|l|}{$\begin{array}{l}\text { Model } 1 \\
\text { (null model) }\end{array}$} & \multicolumn{2}{|c|}{$\begin{array}{l}\text { Model } 2 \\
\text { (plus age, sex, and household income) }\end{array}$} & \multicolumn{2}{|c|}{$\begin{array}{l}\text { Model } 3 \\
\text { (plus area disadvantage) }\end{array}$} \\
\hline & 50.46 & & 40.43 & & 29.55 & \\
\hline Fixed effects & & & Est & $95 \% \mathrm{Cl}$ & Est & $95 \% \mathrm{Cl}$ \\
\hline Age of main food purchaser & & & 0.34 & 0.27 to 0.41 & 0.33 & 0.26 to 0.40 \\
\hline $\begin{array}{l}\text { Sex of main food purchaser (male) } \\
\text { Household income }\end{array}$ & & & -10.74 & -13.25 to -8.23 & -10.69 & -13.20 to -8.18 \\
\hline$\$ 52000$ or more & & & - & - & - & - \\
\hline$\$ 36400-51999$ & & & -0.68 & -3.62 to 2.24 & -0.44 & -3.39 to 2.50 \\
\hline$\$ 20800-36399$ & & & -5.76 & -8.55 to -2.98 & -5.29 & -8.14 to -2.46 \\
\hline$\leqslant \$ 20799$ & & & -8.60 & -11.84 to -5.36 & -7.85 & -11.23 to -4.48 \\
\hline Area socioeconomic disadvantage $†$ & & & & & 2.01 & -0.49 to 4.50 \\
\hline Random effects variance & Est. & SE & Est. & SE & Est. & SE \\
\hline Level 2 (areas) & 12.94 & 5.81 & 5.58 & 3.85 & 4.69 & 3.65 \\
\hline Level 1 (individual) & 304.03 & 14.16 & 262.79 & 12.24 & 262.79 & 12.23 \\
\hline Deviance & 8328.02 & & 8174.04 & & 8171.61 & \\
\hline Intraclass correlation (\%)‡ & 4.08 & & 2.08 & & 1.74 & \\
\hline
\end{tabular}

*The fruit purchasing index ranged from 0-100, with higher scores indicating a wider variety and greater regularity of fruit purchase. $†$ Expressed as a two standard deviation effect size. †The proportion of the total variance in fruit purchasing behaviour that is between the census collectors districts (small urban areas).

household income. After controlling for household income, and the age and sex of respondents, a two standard deviation increase on the area SES measure produced a modest increase of 2.01 units on the fruit purchasing index, with the $95 \%$ confidence limits including zero $(-0.49$ to 4.50$)$, and very small unit increases for the vegetable $(0.60,95 \%$ CI -1.36 to 2.56$)$ and grocery indices $(0.94,95 \% \mathrm{CI}-1.35$ to 3.23). A two standard deviation change in area SES was equivalent to the difference in score between the median values for the top and bottom quartiles of the area SES measure, enabling an approximate comparison with the effect sizes between the high and low categories of household income. This comparison shows that the area SES effect for fruit purchasing was only about $25 \%$ of the household income association, and about $10 \%$ of the income association for vegetable and grocery purchase.

Our findings of a null, or at best modest association of area SES with food purchasing behaviour suggest that urban areas in Brisbane are not highly differentiated on the basis of food availability, accessibility, or affordability—unlike the US and Britain, where living in a socioeconomically disadvantaged area seems to act as a hindrance to the procurement and consumption of healthy food. US research has shown that socioeconomically disadvantaged neighbourhoods are underserved by supermarkets relative to more advantaged $\operatorname{areas}^{24} 26293549$ and that intakes of fruits and vegetables are linked with the number of supermarkets in a neighbourhood. ${ }^{25}$ This work is consistent with results reported by ecological studies conducted in Britain. ${ }^{12} 27281$ There is little Australian research that can be used to help interpret the essentially negative findings of this multilevel study, however, some research does exist, and it provides evidence (albeit indirect) supporting the probable limited impact of contextual or neighbourhood effects on food purchasing in Brisbane. Two studies published in the early 1990s reported that foods being recommended in the Australian Dietary Guidelines were affordable by low income families; indeed, some diets based on the guidelines were actually cheaper than a more traditional diet. ${ }^{5051}$ A later representative study of the Brisbane population in 1993, found that although socioeconomic groups differed significantly in terms of their food purchasing choices, most respondents from all socioeconomic groups shopped at large supermarkets where dietary guideline food was readily available, few reported difficulties accessing these shops, and the price difference between recommended and regular foods was, in most cases, small or non-existent. ${ }^{38}$ Furthermore, as part of the BFS, we collected information on the number and types of food shops, and their location and distance vis a vis the sampled households, and preliminary (unpublished) results are suggesting that socioeconomically advantaged and disadvantaged areas of Brisbane are similarly served by food shops.

Table 4 Area and individual level effects on vegetable purchasing (random intercept models)*

\begin{tabular}{|c|c|c|c|c|c|c|}
\hline \multirow{2}{*}{$\begin{array}{l}\text { Areas }=50 \\
\text { Individuals }=970 \\
\text { Constant }\end{array}$} & \multicolumn{2}{|l|}{$\begin{array}{l}\text { Model } 1 \\
\text { (null model) }\end{array}$} & \multicolumn{2}{|c|}{$\begin{array}{l}\text { Model } 2 \\
\text { (plus age, sex, and household income) }\end{array}$} & \multicolumn{2}{|c|}{$\begin{array}{l}\text { Model } 3 \\
\text { (plus area disadvantage) }\end{array}$} \\
\hline & 61.81 & & 57.52 & & 54.27 & \\
\hline Fixed effects & & & Est & $95 \% \mathrm{Cl}$ & Est & $95 \% \mathrm{Cl}$ \\
\hline Age of main food purchaser & & & 0.17 & 0.11 to 0.24 & 0.17 & 0.11 to 0.23 \\
\hline $\begin{array}{l}\text { Sex of main food purchaser (male) } \\
\text { Household income }\end{array}$ & & & -9.11 & -11.34 to -6.88 & -9.10 & -11.34 to -6.87 \\
\hline$\$ 52000$ or more & & & - & - & - & - \\
\hline$\$ 36400-51999$ & & & -0.06 & -2.65 to 2.53 & 0.03 & -2.57 to 2.65 \\
\hline$\$ 20800-36399$ & & & -1.93 & -4.39 to 0.52 & -1.75 & -4.28 to 0.77 \\
\hline$\leqslant \$ 20799$ & & & -6.27 & -9.11 to -3.44 & -5.97 & -8.97 to -2.97 \\
\hline Area socioeconomic disadvantage $\dagger$ & & & & & 0.60 & -1.36 to 2.56 \\
\hline Random effects variance & Est & SE & Estł & SE & Est & SE \\
\hline Level 2 (areas) & 2.20 & 2.81 & 0.00 & 0.00 & 0.00 & 0.00 \\
\hline Level 1 (individual) & 230.58 & 10.73 & 211.20 & 9.59 & 211.12 & 9.58 \\
\hline Deviance & 8038.58 & & 7944.99 & & 7944.63 & \\
\hline Intraclass correlation (\%)§ & 0.94 & & 0.00 & & 0.00 & \\
\hline
\end{tabular}

*The vegetable purchasing index ranged from 0-100, with higher scores indicating a wider variety and greater regularity of fruit purchase. $†$ Expressed as a two standard deviation effect size. ҒSee Snijders and Bosker (page57) for a discussion of why level 2 random effects variance can be estimated as zero. ${ }^{48} \S$ The proportion of the total variance in vegetable purchasing behaviour that is between the census collectors districts (small urban areas). 
Table 5 Area and individual level effects on grocery purchasing (random intercept models)*

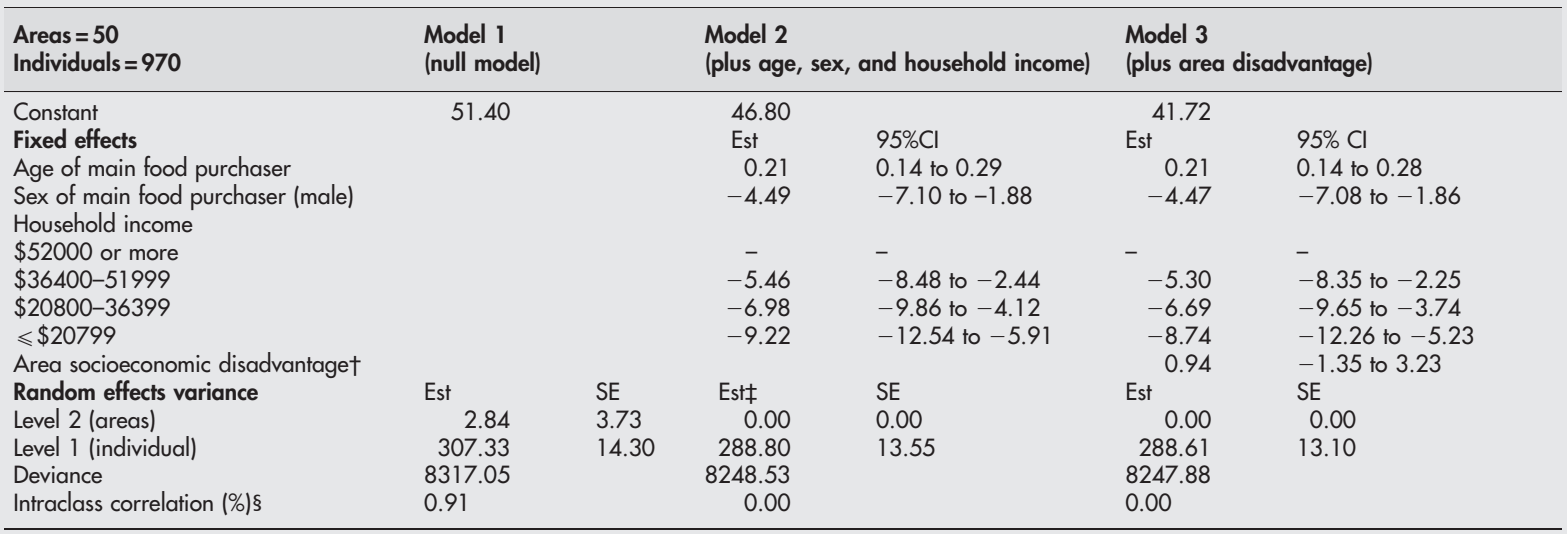

*The grocery purchasing index ranged from $0-100$, with higher scores indicating a greater compliance with dietary guideline recommendations. $\dagger$ Expressed as a two standard deviation effect size. \See Snijders and Bosker (page 57) for a discussion of why level 2 random effects variance can be estimated as zero ${ }^{48} \S$ The proportion of the total variance in grocery purchasing behaviour that is between the census collectors districts (small urban areas).

Importantly, our results and conclusions about the likely limited effect of area SES on food purchasing behaviour in Brisbane needs to be considered against a number of study limitations. Firstly, (and with the benefit of hindsight), our study was seemingly under-powered to detect statistically significant contextual effects. This notwithstanding however, the association of area SES with each outcome variable was in the expected direction, thus while a larger study may have found statistically significant area effects due to increased precision, it is unlikely that a larger sample would have found a substantially increased strength of association between area SES and food purchasing behaviour. Secondly, we only controlled for one individual level socioeconomic factor as a potential confounder (that is, income), which argues against there being any true contextual effect. If we had controlled for other (potentially confounding) individual level socioeconomic factors such as occupation or education, then it is likely that the already weak to moderate area SES effect would have further reduced to the null. Thirdly, it is possible that our study was adversely influenced by selection or information bias, although we are uncertain of the probable magnitude and direction of this bias. As with most multilevel studies $^{5253}$ our areal units were selected for reasons of sampling and analytical convenience rather than for reasons that were hypothesised to influence food purchasing behaviour, and this would probably underestimate area SES associations. Furthermore, non-differential misclassification bias of food purchasing would probably result in an underestimate of the area SES association and the (confounding) income association. In short, the net effect of measurement error in our multilevel study (and multivariable models generally) is unclear. ${ }^{54-56}$ Fourthly, the inclusion of individual level covariates in multilevel analyses may result in overcontrol, which argues for the possibility of a true contextual effect on food purchasing behaviour in Brisbane. Household income, for example, may in part depend on where you live or on cumulative small area effects over the lifecourse. Given each of these limitations, the finding of no significant area SES effect needs to be viewed circumspectly, and further research in a variety of settings is required before more definitive conclusions can be reached.

There is now a large body of Australian and international research that has examined the relation between individual level SES and diet, with diet most often being measured on the basis of food and nutrient intake. ${ }^{8}$ These studies usually find that socioeconomically disadvantaged groups have intakes that are least in accord with minimal risk for the onset of chronic disease. ${ }^{10} 115758$ The individual level results of the BFS adds to this research, and shows that low income households were less likely to purchase foods consistent with recommendations promulgated in diet related promotion messages. For each food type, purchasing score was graded across the income categories, suggesting a high degree of income sensitivity to the purchase of healthy food.

In summary, this first known Australian multilevel study of diet found little evidence that food purchasing behaviour in Brisbane was influenced by area level socioeconomic disadvantage. Thus despite the fact that major urban areas in this country are differentiated on the basis of their social and economic characteristics ${ }^{37}$ this does not seem to be sufficient to shape and circumscribe the procurement of food. It seems that what matters most in Brisbane City in terms of food purchasing behaviour is the socioeconomic characteristics of individuals and their households, rather than the socioeconomic characteristics of the areas in which they live. This Australian finding seems to be in contrast with countries like the US and Britain, where the nature and extent of spatial segregation along social and economic lines is large enough to be detectable in people's dietary behaviour.

\section{Authors' affiliations}

G Turrell, C Patterson, B Oldenburg, School of Public Health, Queensland University of Technology, Brisbane, Queensland, Australia T Blakely, Department of Public Health, Wellington School of Medicine and Health Sciences, University of Otago, Wellington, New Zealand

Funding: funding for this research was provided by a National Health and Medical Research Council Project Grant (no 101217). Dr Turrell is supported by a National Health and Medical Research Council/National Heart Foundation Career Development Award (CR 01B 0502). Dr Blakely is supported by funding from the New Zealand Health Research Council and Ministry of Health.

Conflicts of interest: none declared.

\section{REFERENCES}

1 Kaplan GA, Lynch JW. Whither studies on the socioeconomic foundations of population health. Am J Public Health 1997;87:1409-11.

2 Turrell G, Mathers C. Socioeconomic status and health in Australia. Med J Aust 2000;172:434-8

3 Gaziano JM, Manson JE. Diet and heart disease: the role of fat, alcohol, and antioxidants. Cardiol Clin 1996;14:69-83.

4 Willet WC, Trichopoulos D. Nutrition and cancer: a summary of the evidence. Cancer Causes Control 1996;7:178-80.

5 Swinburn BA, Metcalf PA, Ley SJ. Long term (5 year) effects of a reduced-fat diet intervention in individuals with glucose intolerance. Diabetes Care 2001;24:619-24. 
6 James WPT, Nelson M, Leather S. The contribution of nutrition to inequalities in health. BMJ 1997;314:1545-9.

7 Davey Smith G, Brunner E. Socioeconomic differentials in health: the role of nutrition. Proc Nutr Soc 1997:56:75-90.

8 Turrell G, Hewitt B, Patterson C, et al. Socioeconomic differences in food purchasing behaviour and suggested implications for diet-related health promotion. J Hum Nutr Dietet 2002;15:355-64.

9 Rankin JW, Winett RA, Anderson ES, et al. Food purchase patterns at the supermarket and their relationship to family characteristics. Journal of Nutrition Education 1998;30:81-8.

10 De Irala-Estevaz J, Groth M, Johansson L, et al. A systematic review of socioeconomic differences in food habits in Europe: consumption of fruit and vegetables. Eur J Clin Nutr 2000;54:706-14.

11 Giskes K, Turrell G, Patterson C, et al. Socioeconomic differences among Australian adults in consumption of fruits and vegetables and intakes of antioxidants and folate. J Hum Nutr Dietet 2002;15:375-85.

12 Macintyre S, Maciver S, Sooman A. Area, class and health: should we be focusing on places or people? J Soc Pol 1993;22:213-34.

13 Kaplan G. People and places - contrasting perspectives on the association between social class and health. Int J Health Services 1996;26:507-19.

14 Macintyre S, Ellaway A, Cummins S. Place effects on health: how can we conceptualise, operationalise, and measure them? Soc Sci Med 2002;55: 125-39.

15 Forsyth A, Macintyre S, Anderson A. Diets for disease? Intraurban variation in reported food consumption in Glasgow. Appetite 1994;22:259-74.

16 Ellaway A, Macintyre S. Does where you live predict health related behaviours? A case study in Glasgow. Health Bull 1996;54:443-6.

17 Braddon FEM, Wadsworth MEJ, Davies JMC, et al. Social and regional differences in food and alcohol consumption and their measurement in a national birth cohort. J Epidemiol Community Health 1988;42:341-9.

18 Blaxter M. Health and lifestyles. London: Tavistock/Routledge, 1990.

19 Ecob R, Macintyre S. Small area variations in health related behaviours: do these depend on the behaviour itself, its measurement, or on personal characteristics? Health and Place 2000;6:261-74.

20 Karvonen S, Rimpela A. Socio-regional context as a determinant of adolescents' health behaviour in Finland. Soc Sci Med 1996;43:1467-74.

21 Karvonen S, Rimpela A. Urban small area variation in adolescents' health behaviour. Soc Sci Med 1997;45:1089-98.

22 Diehr P, Koepsell T, Cheadle A, et al. Do communities differ in health behaviours? J Clin Epidemiol 1993;46:1141-9.

23 Diez-Roux AV, Nieto FJ, Caulfield L, et al. Neighbourhood differences in diet: the Atherosclerosis Risk in Communities (ARIC) Study. J Epidemiol Community Health 1999:53:55-63.

24 Morland K, Wing S, Diez Roux A, et al. Neighborhood characteristics associated with the location of food stores and food service places. Am J Prev Med 2002; 22:23-9.

25 Morland K, Wing S, Diez Roux A. The contextual effect of the local food environment on residents' diets: the Atherosclerosis Risk in Communities Study. Am J Public Health 2002;92:1761-7.

26 Chung C, Myers SL. Do the poor pay more for food? An analysis of grocery store availability and food price disparities. Journal of Consumer Affairs 1999:33:276-96.

27 Caraher M, Dixon M, Lang T, et al. Access to healthy foods: part 1. Barriers to accessing healthy foods: differentials by gender, social class, income and mode of transport. Health Education Journal 1998;57:191-201.

28 Robinson N, Caraher M, Lang T. Access to shops: the views of low income shoppers. Health Education Journal 2000;59:121-36.

29 Alwitt LF, Donley TD. Retail stores in poor neighbourhoods. Journal of Consumer Affairs 1997;31:139-64

30 Barratt J. The cost and availability of healthy food choices in southern Derbyshire. J Hum Nutr Dietet 1997; 10:63-9.

31 Sooman A, Macintyre S, Anderson A. Scotland's health-a more difficult challenge for some? The price and availability of healthy foods in socially contrasting localities in the west of Scotland. Health Bull 1993;51:276-84.

32 Acevedo-Garcia D, Lochner KA, Osypuk TL, et al. Future directions in residential segregation research: a multilevel approach. Am J Public Health 2003;93:215-22
33 Waitzman NJ, Smith KR. Separate but lethal: the effects of economic segregation on mortality in metropolitan America. Milbank $Q$ 1998:76:341-73.

34 Shaw M, Dorling D, Gordon D, et al. The widening gap: health inequalities and policy in Britain. Bristol: the Policy Press, 1999.

35 Kolodinsky J, Cranwell M. The poor pay more? Now they don't even have a store to choose from: bringing the supermarket back to the city. Consumer Interests Annual 2000;46:24-9.

36 Swanstrom T, Dreier P, Mollenkopf J. Economic inequality and public policy: the power of place. City and Community 2002;1:349-72.

37 Australian Bureau of Statistics. Social atlas series. Catalogue numbers 2030.0-2030.8. Canberra: Australian Government Publishing Service, 1998.

38 Turrell G. Structural, material, and economic influences on the food purchasing choices of socioeconomic groups. Aust N Z J Public Health 1996:20:611-17

39 Turrell G, Patterson C, Oldenburg B, et al. The socioeconomic patterning of survey participation and non-response error in a multilevel study of food purchasing behaviour: area- and individual-level characteristics. Public Health Nutr 2003;6:181-9.

40 Australian Bureau of Statistics. Socioeconomic indexes for areas, 1996. Catalogue number 2039.0. Canberra: Australian Government Publishing Service, 1998

41 Australian Bureau of Statistics. Income distribution 1999-2000. Catalogue number 6523.0. Canberra: Australian Government Publishing Service, 2001.

42 Kinsey JD. Food and families' socioeconomic status. J Nutr 1994:124:1878-85s.

43 Commonwealth Department of Health and Family Services. Australian guide to healthy eating. Canberra: Australian Government Publishing Service, 1998.

44 National Health and Medical Research Council. Dietary guidelines for Australians. Canberra: Australian Government Publishing Service, 1992

45 Turrell G. Determinants of healthy food choices in a population-based sample. Am J Health Behav 1998;22:342-57.

46 Mclennan W. National nutrition survey users guide. Canberra: Australian Government Publishing Service, 1998.

47 Rashbash J, Browne W, Goldstein H, et al. A user's guide to MLwiN. London: Centre for Multilevel Modelling, 2000.

48 Snijders T, Bosker R. Multilevel analysis: an introduction to basic and advanced multilevel modelling. London: Sage Publications, 1999.

49 Curtis KA, McClellan S. Falling through the safety net: poverty, food assistance and shopping constraints in an American city. Urban Anthropology 1995:24:93-135.

50 Maggiore $\mathbf{P}$. is a healthy diet affordable for families on a low income? Australian Journal of Nutrition and Dietetics 1991;48:38-9.

51 Lawson JS. Food consumption based on dietary guidelines can cost less than traditional diets. Aust J Public Health 1993;17:397-8.

52 Boyle MH, Willms JD. Place effects for areas defined by administrative boundaries. Am J Epidemiol 1999;149:577-85

53 Curtis S, Jones I. Is there a place for geography in the analysis of health inequality? Sociology of Health and Illness 1998;20:645-72.

54 Phillips A, Davey Smith G. How independent are "independent" effects? Relative risk estimation when correlated exposures are measured imprecisely. J Clin Epidemiol 1991;44:1223-31.

55 Marshall J, Hastrup J, Ross J. Mismeasurement and the resonance of strong confounders: correlated errors. Am J Epidemiol 1999;150:88-96.

56 Blakely T. Estimating direct and indirect effects: fallible in theory, but in the real world? Int J Epidemiol 2002;31:166-7.

57 Milligan RA, Burke V, Beilin $\amalg$, et al. Influence of gender and socioeconomic status on dietary patterns and nutrient intakes in 18 year old Australians. Aust N Z J Public Health 1998;25:389-95.

58 Billson H, Pryer JA, Nichols R. Variation in fruit and vegetable consumption among adults in Britain: An analysis from the dietary and nutritional survey of British adults. Eur J Clin Nutr 1999;53:946-52. 